\title{
VIBRATION OF FOUNDATION FOR ROTARY SCREW COMPRESSORS INSTALLED ON SKID MOUNTING
}

\author{
Marina Cerpinska, Martins Irbe, Rihards Elmanis-Helmanis \\ Riga Technical University, Latvia \\ marina.cerpinska@rtu.lv, martins.irbe@ rtu.lv, rihards.elmanis-helmanis@ast.lv
}

\begin{abstract}
The paper is devoted to vibration of the foundations for rotary screw compressors used for gas compression for thermo power plant installed on skid mounting. To evaluate the compressor vibration according to the industry standard VDI 3836, the user should decide whether the foundation is rigid or resilient. The foundation is rigid, if the vertical natural frequency of the foundation is at least $25 \%$ higher than the excitation frequency. The excitation frequency, compressor running speed in $\mathrm{Hz}$ is normally known, while the natural frequency is usually not known. Therefore the goal of the study was to find natural frequencies of the skid using analytical calculations, SolidWorks simulation and "bump testing" on site. In the results section it is shown that vibration in axial direction is usually higher for screw compressors than in radial direction, therefore the mathematical model with compressor shaking horizontally was adopted for this study. Limitations of the bump test were discovered. The examples of distinctive and indistinctive spectrum were presented. It was concluded that for the structure of screw compressor foundation the bump testing on site is rather an ineffective tool to detect natural frequencies, because there are too many frequencies appearing in the spectrum and no natural frequencies could be distinguished from the time waveform. Therefore, testing of the equipment foundation natural frequencies has to be performed in the manufacturing facility before installing the equipment and filling the frame with concrete.
\end{abstract}

Keywords: compressor, foundation, skid, natural frequency.

\section{Introduction}

This paper is devoted to structural vibration of the foundations for large vibrating machines, specifically the screw compressors installed on the skid mounting. Although screw compressors "have the advantage of low mechanical vibration levels" [1], according to our practical observations in recent years compressor and vacuum pump foundations bothered users the most. When the vibration is high, and the equipment is not yet installed on site, meaning that foundation beams design could still be altered, the problem could be solved quite effectively. Sometimes, the equipment is already installed on site and the concrete layer is already added, so changing the design of the foundation without the major overhaul is impossible.

In practice compressors vibrate more than pumps and motors, consequently the recently published standard [2] has higher acceptable vibration values for the compressors. Rotary screw compressors are in general "susceptible to any change in either inlet or discharge conditions", like pressure, temperature, gas volume [3]. The axial movement and high axial vibration is, on the one side, typical for rotary screw compressors, but on the other side, high vibration raises concerns, since screw compressors have small clearances between the male and female rotors [3], and small clearance between the rotor and clearance [1], therefore compressors do not tolerate excessive axial movement [3] or speeds greater than critical, when vibration is too high [1].

To decide on the evaluation criteria of the vibration, one should first decide, if the foundation of the machine is rigid or resilient. As truly noted by Siemens researchers, the foundation may seem to be very stiff, but it must be taken into account that it rests on soft and high lateral supports [4]. For the rigid foundation the acceptable vibration criteria are lower. In reality compressors on site may be installed on the foundation, which could be described neither as block-type foundation, nor pedestal foundation. Rather it is a combination of concrete foundation, main skid and pedestals of the driver and compressor, where concrete foundation compensates the flexibility of skid and pedestals. According to DIN 4024 Part 1 there are the following types of machine foundations: table foundation, spring foundation, slab and platform foundation [5]. For the screw compressors presented in this paper elevated pedestal foundation includes a base slab and vertical columns helping a grid of beams at the top on which the skid established equipment rests. Concrete foundation should compensate the flexibility of skid and pedestals. Concrete should be of at least B 25 strength class and reinforcing steel should be at least of grade St 37-2[5]. According to the machinery foundation and grouting theory, when the compressor is installed on skid mounting, typical static load from the equipment weight on 
the load bearing surface is $0.35-0.7 \mathrm{~kg} \cdot \mathrm{cm}^{-2}$ and typical total load on the load bearing surface is 3.5 $7 \mathrm{~kg} \cdot \mathrm{cm}^{-2}$ [6]. This requires minimum compressive strength of epoxy grout at operating temperature to be at least $21 \mathrm{~kg} / \mathrm{cm}^{2}$ to prevent creep [6]. The natural frequency of the machine support should not match the excitation frequency. To study the natural frequencies of the foundation SolidWorks simulation was completed for simple machine support.

Both wet and dry screw compressors generate pulsation at multiples of the pocket-passing frequency (PPF), which is defined as the number of lobes on the male rotor multiplied by the compressor running speed in Hz [7]. The PPF or gas pulsation frequency GPF could be rather high for axial direction, as presented in the results section Table 1 . However, the users should be very careful when simply diagnosing axial vibration as normal, because the value was great since the installation. Excessive compressor vibration could be a sign that the equipment is working in the generation mode far from optimum, when the discharge pressure is above rating or the speed is too high[3]. Even worse, vibration could be a signal of installation defects like improperly placed grout [3], levelling wedges left under the compressor [3] or foundation bolts loose [3]. Finally, if the foundation is uneven, the compressor will rock [3] and vibrate more.

\section{Materials and methods}

Practical measurements are presented for three rotary screw compressors used for gas compression for a thermopower plant with the $1400 \mathrm{~kW}$ rated power, rotational speed $2968 \mathrm{rpm}$, driven by a three-phase induction motor of $10.5 \mathrm{kV}$. The compressors have rotors in 4-6 configuration, meaning that there are 4 lobes on the main (male) rotor and 6 lobes on the gate (female) rotor.

Modelling part presents a mathematical model of screw compressor table type foundation vibrating axially with the gas pulsation frequency, including calculation of natural frequencies of the beams for compressor foundation using approximated mathematical model of [8], Case history 4.5.

The natural frequency or the first bending mode of the support system could be calculated analytically according to formula (1):

$$
f_{n}=\sqrt{\frac{k_{\text {system }}}{m}}
$$

where $f_{n}$ - natural frequency, rpm;

$m$ - mass, $\mathrm{kg}$;

$k_{\text {system }}$ - stiffness of the system, $\mathrm{kg} \cdot \mathrm{m}^{-1}$, which equals to multiplication of the support number and stiffness as shown in formula (2) for four supports:

$$
k_{\text {system }}=4 \cdot k_{\text {guided }}=4 \cdot\left(\frac{12 \cdot E_{\text {steel }} \cdot I_{y y}}{L^{3}}\right),
$$

where $E_{\text {steel }}-$ Modulus of elasticity, $\mathrm{kg} \cdot \mathrm{m}^{-2}$;

$I_{y y}$ - moment of inertia, $\mathrm{m}^{4}$;

$L-$ length of one support, $\mathrm{m}$.

To obtain more than the first bending mode, SolidWorks simulation of natural frequencies was performed. The supports are $3.048 \mathrm{~m}$ long, assuming there is a piping system below the platform. The supports consist of rectangular tubes, being $3 \mathrm{~mm}$ thick. Simulation is done considering the compressor weight $362.87 \mathrm{~kg}$ and movement in axial direction. Shaking frequencies arising from mechanical unbalance, misalignment or looseness are matching the first rotational frequency $3000 \mathrm{rpm}$. The shaking frequency in axial direction arising from gas pulsation frequency is four times higher, considering the screw compressor has four lobes; therefore it is $12000 \mathrm{rpm}$ or $200 \mathrm{~Hz}$.

To obtain axial and radial vibration results SKF Microlog CMXA 70 device was used. The device was equipped with an accelerometer of type CMSS2200 and sensitivity $100 \mathrm{mV} \cdot \mathrm{g}^{-1}$. The same equipment was used to perform the "bump test" using the methodology explained in the technical paper [9]. For the impact necessary for the "bump test" two excitation tools were used - a rubber hammer and the metal weightlifting accessory of $24 \mathrm{~kg}$. To get the spectrum results after the impact 
and to get read-outs of the spectrum and time waveform of the system natural frequencies SKF @ ptitude Analyst software was used.

\section{Results and discussion}

Vibration problems often occur on the discharge sides of screw compressors [10]. Table 1 presents some practical results of vibration of three rotary screw compressors of similar design, measured on the casing at the non-drive end of the compressor. The purpose of Table 1 is to testify, whether the vibration in axial direction was higher than in radial direction for particular screw compressors. The test would show whether the model employing horizontal shaking frequencies is correct.

Table 1

\section{Comparison of axial vibration vs. radial vibration}

\begin{tabular}{|l|c|c|c|c|}
\hline Measured unit, year & $\begin{array}{c}\text { Slide valve } \\
\text { position, } \%\end{array}$ & $\begin{array}{c}\text { Radial vibration } \\
X, \mathrm{~mm} \cdot \mathrm{s}^{-1}(\mathrm{RMS})\end{array}$ & $\begin{array}{c}\text { Radial vibration } \\
Y, \mathrm{~mm} \cdot \mathrm{s}^{-1}(\mathrm{RMS})\end{array}$ & $\begin{array}{c}\text { Axial vibration, } \\
\mathrm{mm} \cdot \mathrm{s}^{-1}(\mathrm{RMS})\end{array}$ \\
\hline Compressor 1, 2018 & 86 & 2.4 & 3.0 & 8 \\
\hline Compressor 1, 2017 & 85.9 & 4.4 & 5.0 & 5.5 \\
\hline Compressor 1, 2016 & 80.4 & 4.6 & 5.1 & 8.5 \\
\hline Compressor 2, 2017 & 55.2 & 2.1 & 1.2 & 5.9 \\
\hline Compressor 2, 2016 & 58.6 & 1.6 & 1.3 & 6.4 \\
\hline Compressor 3, 2018 & 85.1 & 4.2 & 2.6 & 11.8 \\
\hline Compressor 3, 2017 & 54.4 & 4.7 & 2.2 & 8.9 \\
\hline Compressor 3, 2016 & 56.3 & 2.9 & 2.2 & 7.7 \\
\hline
\end{tabular}

Table 1 confirms that vibration in axial direction at the non-drive end is higher, and in extreme cases, two to three times higher for rotary screw compressors irrespective of the slide valve position.

\section{Fundamental frequencies}

For the given mathematical model of [8] the natural frequencies are first calculated in MathCad. For the system consisting of hollow rectangular cross-section support natural frequency was calculated to be $46.31 \mathrm{rad} \cdot \mathrm{s}^{-1}$ or $7.37 \mathrm{~Hz}$. For the system consisting of hollow rod cross-section support natural frequency was calculated to be $140.5 \mathrm{rad} \cdot \mathrm{s}^{-1}$ or $22.36 \mathrm{~Hz}$.

The SolidWorks simulation shows results for the system consisting of hollow rectangular crosssection support, modes up to $5^{\text {th }}$ in Table 2 and respective graphical results in Fig. 1. The first bending mode at frequency $6.5 \mathrm{~Hz}$ is close to the natural frequency calculated in Mathcad, equal to $7.37 \mathrm{~Hz}$. The difference of $0.87 \mathrm{~Hz}$ appears since in the SolidWorks simulation the stiffness of the total system would be different. For instance, the top frame located on the support was not ignored in the calculation. According to formula (1), the higher the stiffness, the higher the natural frequency. This means that just by multiplying the number of supports with the stiffness of one support, the total stiffness of the system is a little bit higher.

Table 2

Frequency results for $1^{\text {st }}-5^{\text {th }}$ mode from SolidWorks simulation

\begin{tabular}{|c|c|c|c|}
\hline Mode Number & $\begin{array}{c}\text { Angular frequency, } \\
\text { rad·sec }^{-1}\end{array}$ & Frequency, Hz & Period, $\mathbf{s}$ \\
\hline 1 & 40.9 & 6.5 & 0.15 \\
\hline 2 & 41.2 & 6.5 & 0.15 \\
\hline 3 & 65.2 & 10.4 & 0.096 \\
\hline 4 & 123.9 & 19.7 & 0.05 \\
\hline 5 & 257.6 & 41.0 & 0.02 \\
\hline
\end{tabular}

Users should avoid resonance, and natural frequencies of the foundation should not be too close to $50 \mathrm{~Hz}$ and $100 \mathrm{~Hz}$, which is the operating frequency and double operating frequency of the electrical machines in the countries, where the electrical grid has the frequency of $50 \mathrm{~Hz}$. The results of simulation in Table 2 suggest that all of the frequencies are below the self-excited frequencies, only 
the fifth mode goes a little bit closer to $50 \mathrm{~Hz}$, but it is still very far from gas pulsation frequency $200 \mathrm{~Hz}$
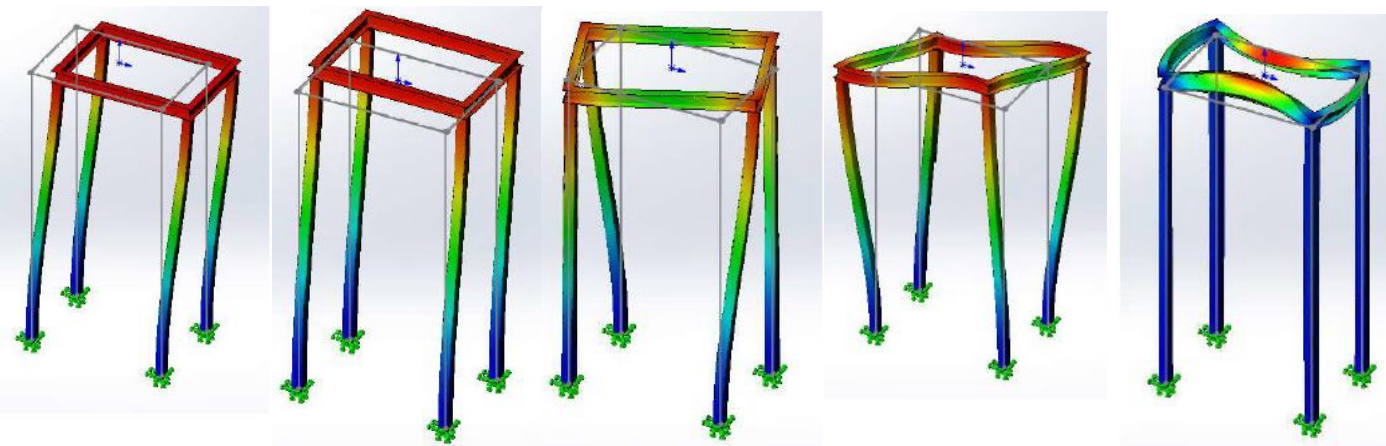

Fig. 1. Simulation of foundation $1^{\text {st }}-5^{\text {th }}$ natural frequency

\section{Spectrum and "Bump test" results}

The maximum generated pulsation levels normally occur at pocket passing frequency $(1 \times \mathrm{PPF})$ and are generally reduced at the higher harmonics; however, in many cases, higher amplitude pulsation can occur at harmonics of the PPF. It is not uncommon to measure significant pulsation up to the 10th harmonic of the PPF [7].

Neither of the excitation frequencies should match the natural frequencies. According to fundamentals of mechanical vibrations [11], the system has as many natural frequencies, as degrees of freedom and masses. Meanwhile, according to DIN 4024 Part 1, "each possible independent displacement of a material point within a spatial configuration is defined as a degree of freedom"[5]. Therefore, the results of practical measurements presented in Table 3 show all natural frequencies of the system registered in the spectrum using the "bump test". The measurements for the vertical direction were selected, because vertical natural frequency is determining the foundation type according to the standard [2].

Table 3

Frequency results from "bump tests"

\begin{tabular}{|c|c|c|c|}
\hline Location & Excitation tool & $\begin{array}{c}\text { Registered } \\
\text { frequencies } \\
\text { under 62.5 Hz }\end{array}$ & $\begin{array}{c}\text { Registered frequencies } \\
\text { over 62.5 Hz }\end{array}$ \\
\hline $\begin{array}{c}\text { Motor foundation, non-drive } \\
\text { end }\end{array}$ & Rubber hammer & - & $192,223,256,384 \mathrm{~Hz}$ \\
\hline Motor foot, drive end & Rubber hammer & $30 \mathrm{~Hz}$ & $115,128,384 \mathrm{~Hz}$ \\
\hline Motor foot, non-drive end & Rubber hammer & - & $192 \mathrm{~Hz}$ \\
\hline $\begin{array}{c}\text { Motor foundation, non-drive } \\
\text { end }\end{array}$ & Rubber hammer & $20 \mathrm{~Hz}$ & $216,256,384 \mathrm{~Hz}$ \\
\hline $\begin{array}{c}\text { Motor foundation, non-drive } \\
\text { end }\end{array}$ & $24 \mathrm{~kg}$ & - & $256,384 \mathrm{~Hz}$ \\
\hline Motor foundation, drive end & $24 \mathrm{~kg}$ & - & $153,172,181,192 \mathrm{~Hz}$ \\
\hline $\begin{array}{c}\text { Compressor foundation, non- } \\
\text { drive end }\end{array}$ & $24 \mathrm{~kg}$ & - & $128,130,133 \mathrm{~Hz}$ \\
\hline $\begin{array}{c}\text { Compressor foundation, } \\
\text { drive end }\end{array}$ & $24 \mathrm{~kg}$ & - & $138,140 \mathrm{~Hz}$ \\
\hline
\end{tabular}

The evaluation of the amplitudes of spectrum harmonics showed that all frequencies in the vibration spectrum with the highest amplitudes are those greater than $62.5 \mathrm{~Hz}$. The frequencies of $20 \mathrm{~Hz}$ and $30 \mathrm{~Hz}$ were registered in some spectrums, but the amplitude of these frequencies was small, and given frequencies could not be red from the time waveform, which suggests they are not true natural frequencies of the given system. This supports the opinion that compressor foundation should be considered rigid using the standard [2]. 
However, Table 3 suggests as well that many supports and added masses make practical measurement of natural frequency of the compressor foundations quite unclear. To illustrate limitations of the bump test on site the results of another bump test (where spectrum and waveform show natural frequency clearly) made for the foundation before instalment are presented in Fig. 2.

a)

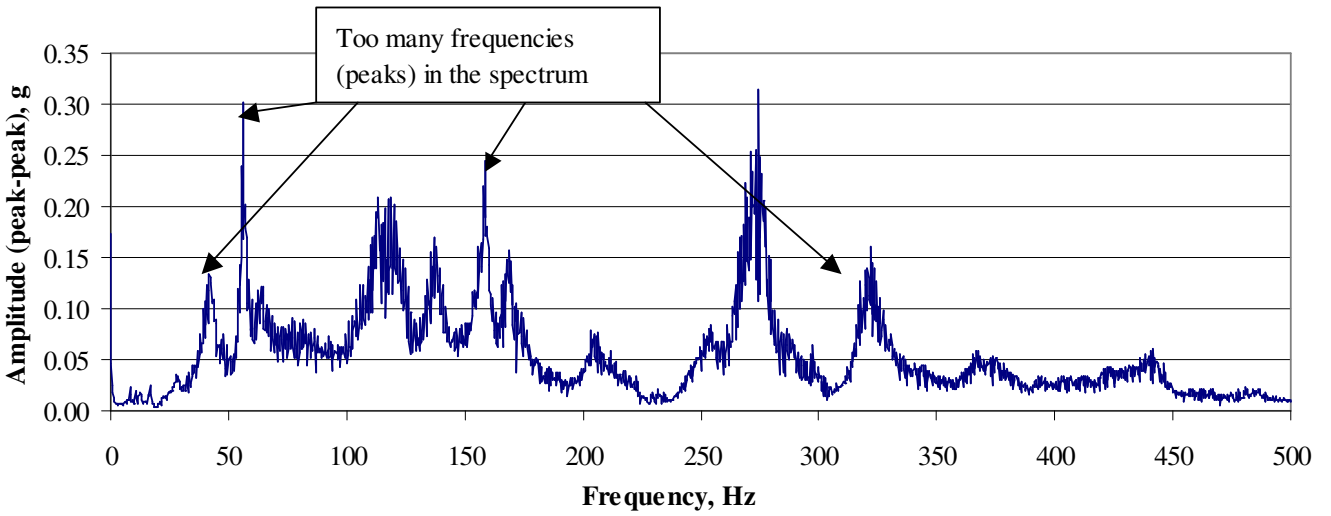

b)

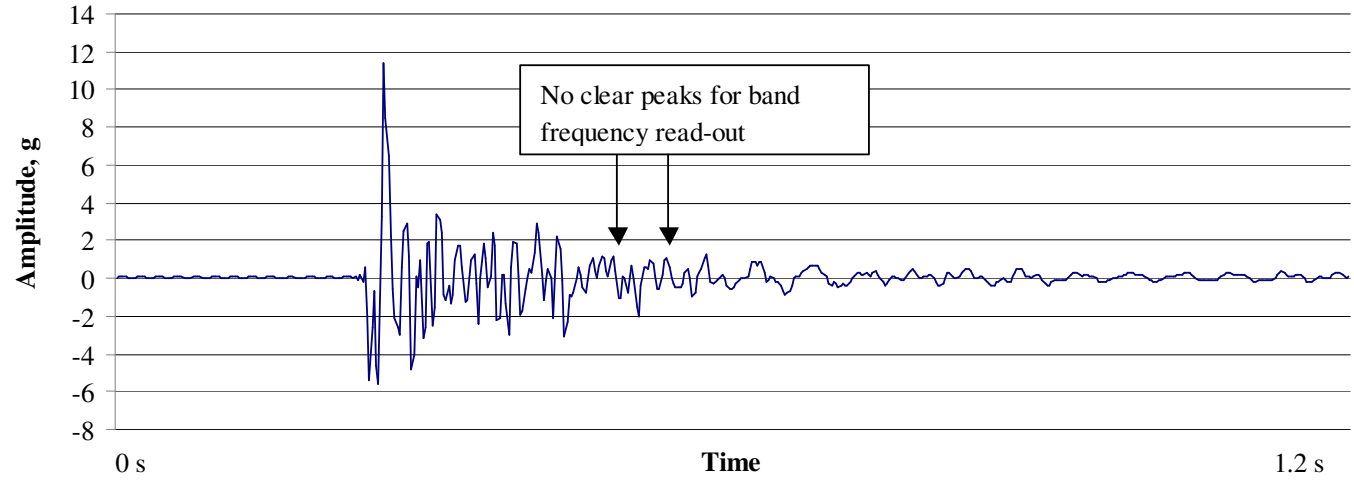

c)

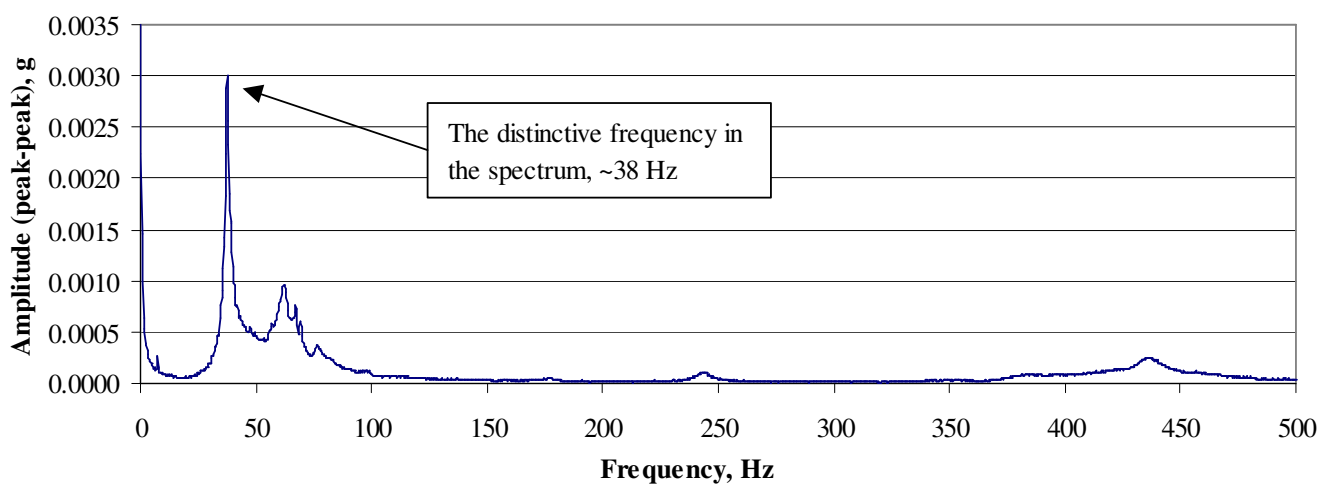

d)

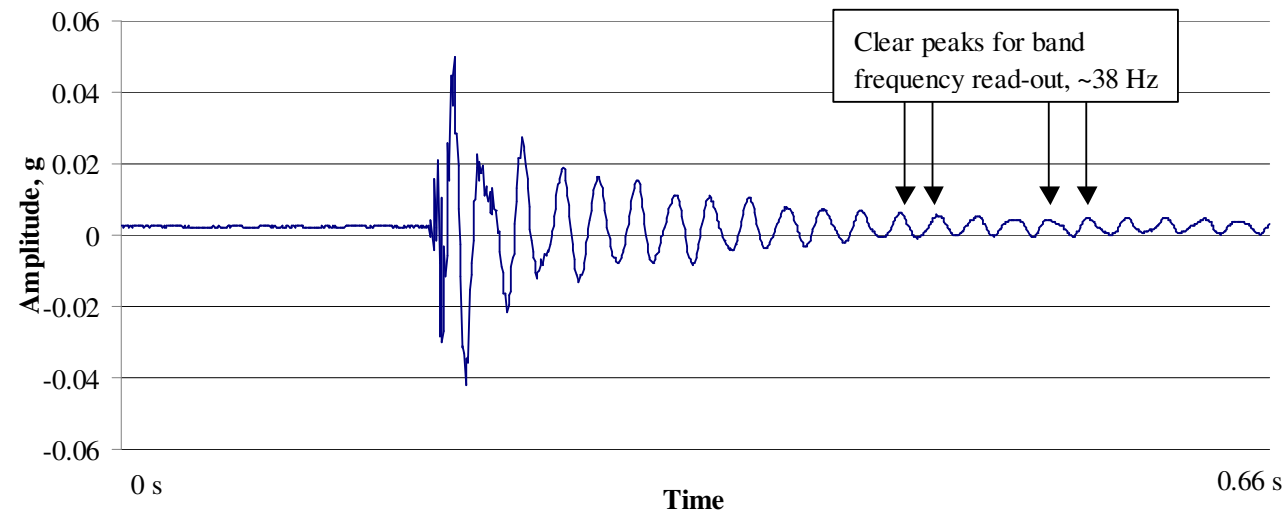

Fig. 2. Bump testing on site and bump testing in factory: a - spectrum results of a poor bump-test experiment on site; $\mathrm{b}$ - time waveform of a poor experiment on site; $\mathrm{c}$ - spectrum results of a successful bump-test experiment in factory; $d$ - time waveform of a successful experiment in factory 
Fig. 2 shows that factory tests of the equipment, where the natural frequencies of the table type foundation were measured before installing the machines on site, were more successful. The natural frequency of $37.5 \mathrm{~Hz}$ could be detected in the spectrum distinctively. In addition, the natural frequency could be easily checked from the waveform [9]. For factory case the distance between two waveform peaks was $38 \mathrm{~Hz}$. For on-site case the waveform was so chaotic that the peaks are not distinctive.

\section{Conclusions}

1. It was confirmed in the results section that the vibration in axial direction was normally higher than in radial direction for particular screw compressors.

2. The simulation section showed that natural frequency of the foundation using SolidWorks modelling is quite close to analytical calculations. The difference of the first bending mode was less than $1 \mathrm{~Hz}$. The bump test results were different, because the screw compressor skid was of more complicated structure than the table type foundation.

3. The spectrum results showed that for the structure of the screw compressor foundation the bump testing on site is rather an ineffective tool to detect natural frequencies.

4. The bump testing of the equipment has to be performed before installing the equipment. Then the results are clear and natural frequencies of the foundation distinctive.

\section{Acknowledgements}

The authors gratefully acknowledge the contributions of Riga Technical University Mechanical Engineering students Nikolajs Leidmans, Vladislava Glomozda and Martin OseDizbite for their work on the simulation part of this project.

\section{References}

[1] Wennemar J. Dry Screw Compressor Performance and Application Range. Proceedings of the Thirty-Eighth Turbomachinery Symposium, Turbomachinery Laboratory, 2009, Texas, pp. 149-156.

[2] VDI 3836:2012-Measurement and evaluation of mechanical vibration of screw-type compressors and root blowers. Addition to DIN ISO 10816-3.SAI Global.

[3] Smith R., Mobley R.K. Rules of thumb for maintenance and reliability engineers. ButterworthHeinemann, 2011.320 p.

[4] Horst K., Siegl G., Woywode P. Influence of elastic foundation structures on the rotor dynamics of drive trains. Proceedings of5th IEEE Petroleum and Chemical Industry Conference - Electrical and Instrumentation Applications,2008, Europe, pp. 1-8.

[5] DIN 4024 Part 1: Machine foundations; elastic supporting constructions for machines with rotating masses. 1988.

[6] Bloch H.P., Geitner F.K. Machinery Component Maintenance and Repair: Practical Machinery Management for Process Plants. Vol. 3.,2005. 650 p.

[7] Smith D.R. Pulsation, vibration, and noise issues with wet and dry screw compressors. Proceedings of the 41st Turbomachinery Symposium, September 24-27, 2012, Houston, Texas, pp. 1-33.

[8] Sofronas A. Case Histories in Vibration Analysis and Metal Fatigue for the Practicing Engineer. First Edition.Texas: John Wiley \& Sons, Inc., 2012. 288 p.

[9] Peters J.D. What's up with bump testing?Technical Resources of CTC University.[online] [01.07.2017]. Available at: https://www.ctconline.com/university/3_advanced/3-02.pdf

[10] Mujić E., Kovačević A., Stošić N., Smith I.K. Reduction of Noise in Screw Compressors. Proceedings of 12th International Research/Expert Conference "Trends in the Development of Machinery and Associated Technology", August 26-30, 2008, Istanbul, Turkey, pp. 1-4.

[11]Rao S.S. Mechanical vibrations. Second edition. Addison-Wesley Publishing Company, 1990. $716 \mathrm{p}$. 